\title{
Isolation and Long-term Cultivation of Mouse Alveolar Macrophages
}

Clara Jana-Lui Busch ${ }^{1,2}$, Jérémy Favret ${ }^{1,2,3}$, Laufey Geirsdóttir ${ }^{3}$, Kaaweh Molawi², 3 and Michael H. Sieweke ${ }^{1,2,3, *}$

\author{
${ }^{1}$ Center for Regenerative Therapies Dresden (CRTD), Technische Universität Dresden, Fetscherstraße \\ 105, Dresden, Germany; ${ }^{2}$ Max-Delbrück-Centrum für Molekulare Medizin in der Helmholtzgemeinschaft \\ (MDC), Berlin, Germany; ${ }^{3}$ Aix Marseille University, CNRS, INSERM, CIML, Marseille, France \\ *For correspondence: $\underline{\text { Michael.sieweke@tu-dresden.de }}$
}

\begin{abstract}
[Abstract] Alveolar macrophages (AM) are tissue-resident macrophages that colonize the lung around birth and can self-maintain long-term in an adult organism without contribution of monocytes. AM are located in the pulmonary alveoli and can be harvested by washing the lungs using the method of bronchoalveolar lavage (BAL). Here, we compared different conditions of BAL to obtain high yields of murine $\mathrm{AM}$ for in vitro culture and expansion of $\mathrm{AM}$. In addition, we describe specific culture conditions, under which AM proliferate long-term in liquid culture in the presence of granulocyte-macrophage colony-stimulating factor. This method can be used to obtain large numbers of AM for in vivo transplantation or for in vitro experiments with primary mouse macrophages.
\end{abstract}

Keywords: Macrophage, Alveolar, Lungs, Self-renewal, Bronchoalveolar lavage, Primary cell culture

[Background] AM are resident tissue macrophages of the lungs with critical importance for immune regulation and surfactant homeostasis (Kopf et al., 2015). Due to their localization in the airspace of the alveoli, AM are directly exposed to inhaled air and pathogens or other aerosolized particles. Consequently, AM play a crucial role in the initiation or suppression of inflammatory responses and are the subject of investigation in numerous studies that explore mechanisms of pulmonary diseases (Hodge et al., 2007; Sun and Metzger, 2008; Happle et al., 2014; Schneider et al., 2014a; Machiels et al., 2017; Yu et al., 2017). Interestingly, AM in the mouse originate from fetal monocytes and are able to selfmaintain their numbers in vivo without contribution of bone-marrow-derived monocytes under steady state conditions (Guilliams et al., 2013; Hashimoto et al., 2013). AM are unique in that they reside outside of the body surface and are directly exposed to the external environment. They can therefore be isolated with minimal tissue disturbance using bronchoalveolar lavage (BAL). We previously demonstrated that the self-renewal property of AM harvested by BAL is maintained in culture by growing AM long-term in liquid media or serially re-plating AM in semi-solid media (Soucie et al., 2016; Imperatore et al., 2017). Here, we describe the methodological advancements in BAL and specific culturing conditions optimized for long-term culture and high AM yields.

To obtain sufficient quality and numbers of $A M$, we tested different cell harvesting conditions and developed a culture method that allows long-term maintenance of AM in vitro. Our BAL method was based on earlier studies using pre-warmed PBS and EDTA for detaching AM from lung alveoli (Steele et al., 2003; Zhang et al., 2008). Additionally, serum was added for cellular protection during the isolation 
period. Importantly, both omitting EDTA in the lavage buffer and using pre-cooled PBS for lavage resulted in lower AM yield in our hands. Our comparisons demonstrated that the variable with the largest effect on yield was the temperature of the BAL buffer (Figure 1). Whereas many earlier studies obtain BAL cell numbers below $2 \times 10^{5}$ per wild-type mouse (Table 1), our comparative analysis indicated that BAL cell numbers can be considerably increased by these optimizations. We generally obtained up to $5 \times 10^{5}-7 \times 10^{5}$ live (Trypan-Blue-negative) cells per mouse using this method (Figure 1). FACS analysis revealed that more than $98 \%$ of cells were alive at the time of recording using the Zombie Violet Fixable Viability Kit, independent of whether the BAL was performed with $4{ }^{\circ} \mathrm{C}$ PBS or $37{ }^{\circ} \mathrm{C}$ PBS/EDTA/FBS. Our experience has shown that when performing dozens of BALs on the same day long waiting times on ice will result in higher cell death unless low amounts of FBS are added to the BAL buffer (typically $0.5 \%$, although we have good experience with up to $2 \%$ ).

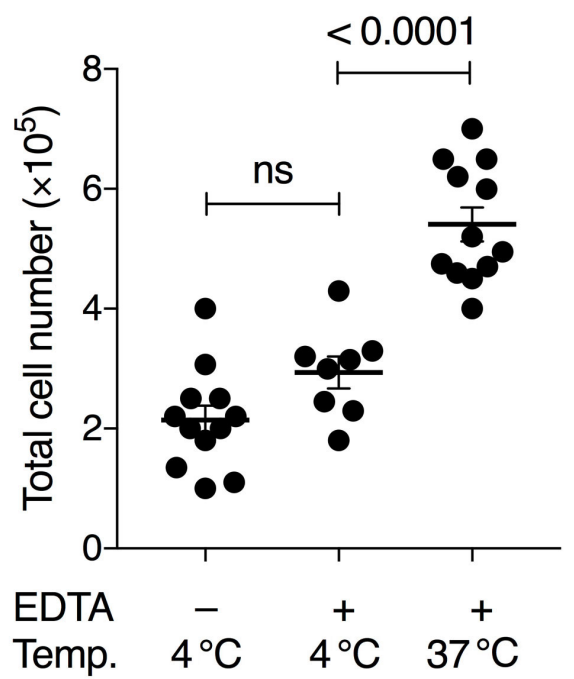

Figure 1. Comparison of BAL conditions using pre-cooled or pre-warmed PBS with or without 2 mM EDTA. Either $4{ }^{\circ} \mathrm{C}$ PBS without EDTA, $4{ }^{\circ} \mathrm{C}$ PBS with $2 \mathrm{mM}$ EDTA and $0.5 \% \mathrm{FBS}$, or $37^{\circ} \mathrm{C}$ PBS with $2 \mathrm{mM}$ EDTA and 0.5\% FBS was used. Numbers show the total amount of living cells (Trypan-Blue-negative) per BAL treatment per mouse. Each symbol denotes the mean cell count of 3 technical replicates of an individual mouse; horizontal lines indicate the mean, error bars show standard error of the mean (SEM); one-way ANOVA with Tukey's multiple comparisons test; ns, non-significant. 
Table 1. Comparison of the efficiency of different BAL protocols. Total cell number in BAL fluid obtained in cited studies. Only counts from WT animals (or comparable conditions, such as controltreated WT animals) were considered. WT denotes wild-type mouse.

\begin{tabular}{lllll}
\hline Mouse strain & Total cell number & Volume & Buffer conditions & References \\
\hline WT (4 weeks) & 20,000 & $2 \times 0.4 \mathrm{ml}$ & $0.5 \mathrm{mM}$ EDTA & Yu et al., 2017 \\
WT (control) & 40,000 & $2 \times 0.8 \mathrm{ml}$ & & Yuan et al., 2015 \\
WT (floxed) & $30-40,000$ & $3 \times 0.4 \mathrm{ml}$ & & Schneider et al., 2014b \\
WT (control) & 50,000 & $2 \times 1 \mathrm{ml}$ & EDTA, $4{ }^{\circ} \mathrm{C}$ & Machiels et al., 2017 \\
WT & 60,000 & $3 \times 0.4 \mathrm{ml}$ & & Schneider et al., 2014a \\
WT (6 weeks) & $50-150,000$ & $3 \times 1 \mathrm{ml}$ & $0.5 \mathrm{mM}$ EDTA & van de Laar et al., 2016 \\
WT (1 year) & $100-200,000$ & $3 \times 1 \mathrm{ml}$ & $0.5 \mathrm{mM}$ EDTA & van de Laar et al., 2016 \\
WT (control) & 250,000 & $5 \times 1 \mathrm{ml}$ & $5 \mathrm{mM}$ EDTA & Qian et al., 2018 \\
WT (1 year) & $250-300,000$ & $5 \times 1 \mathrm{ml}$ & & Suzuki et al., 2014 \\
WT & $300-500,000$ & $3 \times 2 \mathrm{ml}$ & $0.5 \mathrm{mM}$ EDTA, 37 ${ }^{\circ} \mathrm{C}$ & Zhang et al., 2008 \\
WT & $400-500,000$ & $3 \times 1 \mathrm{ml}$ & $2 \%$ BSA, 2 mM EDTA & Dong et al., 2018 \\
WT (6-8 weeks) & $500-700,000$ & $10 \times 1 \mathrm{ml}$ & $0.5 \% \quad$ FBS, $2 \quad \mathrm{mM}$ & Soucie et al., 2016, Imperatore et al., \\
& & & EDTA, 37 ${ }^{\circ} \mathrm{C}$ & 2017 and this study \\
\hline
\end{tabular}

Increased efficiency in harvesting BAL cells is advantageous for in vivo reconstitution of multiple recipient animals such as strains devoid of endogenous AM, such as GM-CSF-receptor-deficient mice (Guilliams et al., 2013; van de Laar et al., 2016). High starting cell numbers and viability of harvested cells will accelerate establishment of long-term AM cultures and improve cellular yield. We also noticed several culture conditions outlined in the detailed protocol that affect the quality, yield, doubling time and durability of the cultures. In order to avoid cell activation or death, several parameters need to be controlled. Firstly, we used exclusively sterile supplies and applied sterile handling techniques to avoid activation of AM. Secondly, we use non-treated plastic ware (not tissue-culture treated plates or dishes) and a gentle detachment protocol. Together, these technical improvements will be helpful for starting and maintaining a long-term AM culture.

Biochemical and genetic manipulations of macrophages that require a large number of cells could so far only be done in cell lines, such as RAW 264.7 or J774A.1 cells (Ralph and Nakoinz, 1975; Raschke et al., 1978), oncogene-transformed cells, for example Myc (Baumbach et al., 1986; Baumbach et al., 1987) or SV40 transformed macrophages like IC-21 (Walker and Demus, 1975) or MH-S cells (Mbawuike and Herscowitz, 1989), macrophages differentiated from progenitors (Zhang et al., 2008; Fejer et al., 2013) or non-transformed but genetically modified macrophages, such as Maf-DKO macrophages (Aziz et al., 2009). The ability to obtain large numbers of normal unmodified AM in culture allows such experiments in primary resident macrophages. Our studies on macrophage self-renewal mechanisms serve as an example (Soucie et al., 2016; Imperatore et al., 2017).

\section{Materials and Reagents}

1. 15-ml conical tubes (Corning, catalog number: 352196) 
2. Bottle-top vacuum filter with $0.22 \mu \mathrm{m}$ membrane (Corning, catalog number: 431161)

3. Plastic storage bottle (Corning, catalog number: 430281)

4. 70- $\mu \mathrm{m}$ sterile cell strainer (BD, catalog number: 340633 )

5. 1-ml syringe (Braun, catalog number: $9161406 \mathrm{~V}$ )

6. 18-G cannula (Braun, catalog number: 4667123)

7. Petri dish 94/16 mm (Greiner Bio-one, catalog number: 633181)

8. Non-treated 6-well plate (Nunc ${ }^{\mathrm{TM}}$, catalog number: 150239)

9. C57BL/6 mice (aged 6-10 weeks)

10. PBS, pH 7.2 (Thermo Fisher Scientific, Gibco ${ }^{\mathrm{TM}}$, catalog number: 20012019)

11. EDTA stock solution (e.g., $0.5 \mathrm{M}, \mathrm{pH} 8.0$ )

12. Hemolysis buffer (self-made or commercial, e.g., Morphisto, catalog number: 12146)

13. Trypan Blue solution $0.4 \%$ (Sigma-Aldrich, catalog number: T8154)

14. RPMI 1640 Medium, no glutamine (Thermo Fisher Scientific, Gibco ${ }^{\mathrm{TM}}$, catalog number: 31870025)

15. Fetal bovine serum (Testing of different batches is recommended)

16. Gentamicin sulphate $50 \mathrm{mg} / \mathrm{ml}$ in aqueous solution (Lonza, catalog number: BE02-012E)

17. Penicillin-Streptomycin $(10,000 \mathrm{U} / \mathrm{ml})$ (Thermo Fisher Scientific, Gibco ${ }^{\mathrm{TM}}$, catalog number: 15140122)

18. Sodium Pyruvate (100 mM) (Thermo Fisher Scientific, Gibco ${ }^{T M}$, catalog number: 11360070$)$

19. GlutaMAX $X^{\mathrm{TM}}$ Supplement (Thermo Fisher Scientific, Gibco ${ }^{\mathrm{TM}}$, catalog number: 35050038 )

20. Conditioned medium from J558L cell line transfected with murine GM-CSF cDNA as a source for GM-CSF (Zal et al., 1994; Stockinger et al., 1996; Rayasam, 2015)

21. ESGRO Complete Accutase (Merck, catalog number: SF006)

22. EGTA stock solution (e.g., $0.5 \mathrm{M}, \mathrm{pH} 8.0$ )

23. UltraComp eBeads ${ }^{\mathrm{TM}}$ Compensation Beads (Thermo Fisher Scientific, Invitrogen, catalog number: 01-2222-41)

24. Zombie Violet Fixable Viability Kit (BioLegend, catalog number: 423113)

25. FACS antibodies (as indicated in Table 2)

26. BAL buffer (see Recipes)

27. Complete medium (see Recipes)

28. AM culture medium (see Recipes)

29. Detachment medium (see Recipes)

\section{Equipment}

1. Pipettes

2. Mouse dissection tools (scissors, forceps)

3. Water bath set to $37^{\circ} \mathrm{C}$

4. Refrigerated benchtop centrifuge for spinning conical tubes 
5. Hemocytometer (Roth, catalog number: T729.1)

6. Incubator $\left(37^{\circ} \mathrm{C}, 5 \% \mathrm{CO}_{2}\right)$

7. Inverse microscope

\section{Procedure}

A. Harvest alveolar macrophages by bronchoalveolar lavage (BAL)

1. For each mouse, prepare a $15-\mathrm{ml}$ conical tube filled with $3 \mathrm{ml}$ complete medium (see Recipes).

2. Warm-up BAL buffer (see Recipes) to $37^{\circ} \mathrm{C}$ in a water bath. Keep warm during the whole procedure.

3. Euthanize the mouse by cervical dislocation without rupturing the jugular vein or the trachea to avoid exposing $\mathrm{AM}$ to $\mathrm{CO}_{2}$ or isoflurane, which could affect functional properties of $\mathrm{AM}$.

4. Using dissection tools, remove the skin, ribcage and muscles to expose both lungs and trachea. Avoid cutting or rupturing blood vessels.

Note: Since methods for the surgical exposure of lungs and the trachea have been published previously in this journal, the reader is referred to those protocols for instructions (Han and Ziegler, 2013; Tibbitt and Coquet, 2016; Jhingran et al., 2016; Sun et al., 2017).

5. Use a fine scissor to make a small incision in the upper part of the trachea just below the larynx. The part of the trachea facing downwards (away from the experimenter) should remain intact, do not cut through the whole trachea.

6. Use the incision to insert a slightly blunted $18-\mathrm{G}$ cannula and direct the cannula $5 \mathrm{~mm}$ deeper into the trachea towards the lungs. Take care not to damage lung tissue.

7. Attach a $1 \mathrm{ml}$ syringe filled with $1 \mathrm{ml}$ warm BAL buffer onto the inserted cannula.

8. Inject $1 \mathrm{ml}$ buffer while fixating the cannula position with the other hand.

9. Pull the plunger to collect BAL fluid in the syringe. About 800-900 $\mu \mathrm{l}$ can be recovered. Observe that the pressure should not be too high, otherwise the alveoli will burst and BAL fluid will be lost. Upon injection and collection, the lungs should visibly inflate and deflate.

10. Filter collected BAL fluid through a $70 \mu \mathrm{m}$ cell strainer into the $15-\mathrm{ml}$ tube with $3 \mathrm{ml}$ complete medium from Step A1.

11. Repeat Steps A6-A10 for 9 more times each time with fresh warm BAL buffer. Pool cells into the same 15-ml tube.

12. Collect cells by centrifugation at $300 \times \mathrm{g}, 5 \mathrm{~min}$ at $4{ }^{\circ} \mathrm{C}$. Remove supernatant. The cell pellet should be white. A red/pink color indicates that blood was accidentally collected during the BAL.

13. Add $1 \mathrm{ml}$ hemolysis buffer for $2 \mathrm{~min}$ incubation at room temperature to lyse residual erythrocytes. Fill up tube with complete medium to stop lysis and collect cells by centrifugation as before. Remove supernatant. The color of the cell pellet should be white now.

14. Resuspend cell pellet in $500 \mu \mathrm{l} \mathrm{BAL}$ buffer and take a sample for counting using a hemocytometer chamber after staining with Trypan Blue to exclude dead cells. Count only live (Trypan-Blue negative) cells. 
15. Calculate the total cell number per BAL. Typically, $5 \times 10^{5}-7 \times 10^{5}$ live cells per adult wild-type mouse aged 6-8 weeks can be recovered when using pre-warmed BAL buffer, containing PBS with $2 \mathrm{mM}$ EDTA and $0.5 \%$ serum.

16. Proceed to cell staining and flow cytometry analysis or in vitro cultivation.

B. Flow cytometric analysis of alveolar macrophages

1. Block unspecific binding sites on cells with TruStain $\mathrm{fcX}$ and concomitantly stain with Zombie Violet in $200 \mu \mathrm{l}$ cold PBS (without FBS) at $4{ }^{\circ} \mathrm{C}$ in the dark for $15 \mathrm{~min}$ (see Table 2).

2. Wash cells with cold BAL buffer by centrifugation at $300 \times g$ for 5 min at $4{ }^{\circ} \mathrm{C}$.

3. Stain cells in a volume of $100 \mu \mathrm{l}$ per 1 million cells according to Table 2 for $30 \mathrm{~min}$ at $4{ }^{\circ} \mathrm{C}$ in the dark using BAL buffer.

Table 2. FACS reagents used for staining BAL AM

\begin{tabular}{lllll}
\hline & Conjugate & Clone & Dilution & Company, Cat. No. \\
\hline TruStain fcX & - & 93 & $1: 200$ & BioLegend, 101320 \\
\hline ZombieViolet & BV421 & - & $1: 400$ & BioLegend, 423113 \\
\hline SiglecF & PE & E50-2440 & $1: 200$ & BD, 552126 \\
\hline CD11C & PE/Cy7 & N418 & $1: 400$ & BioLegend, 117318
\end{tabular}

4. Prepare compensation beads for each antibody conjugate.

5. Wash cells with BAL buffer, resuspend in $200 \mu \mathrm{l}$ BAL buffer for recording.

6. Record cells by flow cytometry after acquiring the compensation beads. AM are double-positive for SiglecF and CD11c (Figures 2A-2C), and > 98\% viable (Figure 2D). 
A

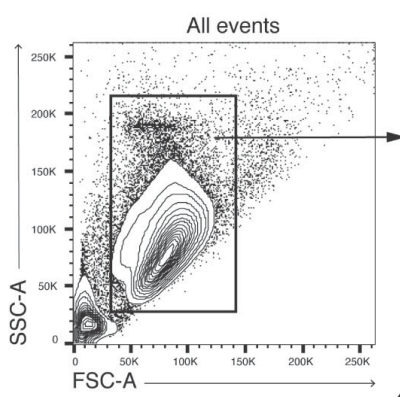

Single cells

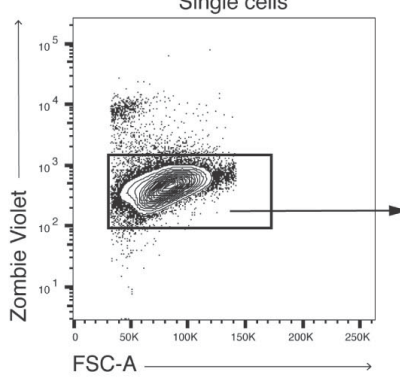

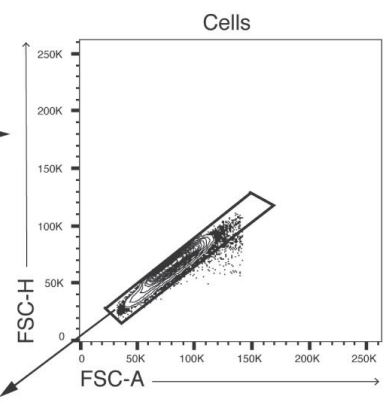

Live cells

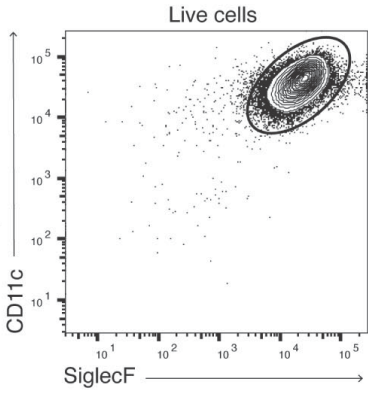

B

C
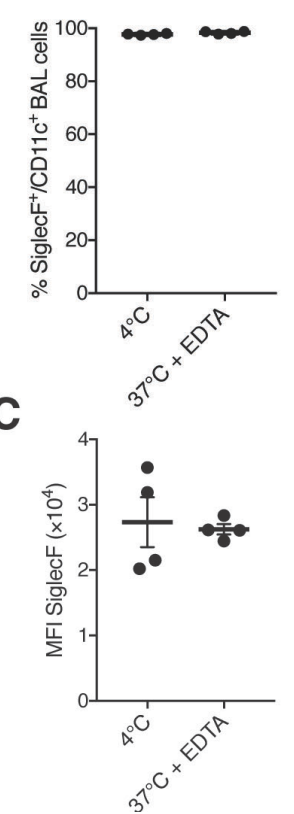

D
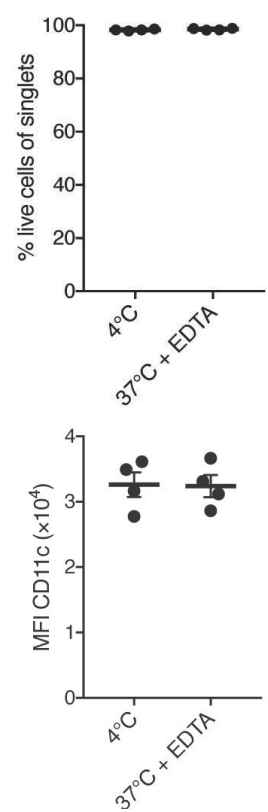

Figure 2. FACS analysis of BAL AM. A. Simple gating strategy for exclusion of doublets, dead cells. AM are SiglecF- and CD11c-positive. B-C. BAL cells harvested with pre-warmed BAL buffer containing EDTA are phenotypically not different from BAL cells harvested using precooled PBS. Each symbol denotes 1 mouse. Typically, $>95 \%$ of BAL cells are AM. D. Viability analysis of BAL singlet cells assessed by staining with Zombie Violet Fixable Dye.

C. Cultivation of alveolar macrophages

1. Collect cells by centrifugation as before. Remove supernatant.

2. Plate $3 \times 10^{5}-4 \times 10^{5}$ cells per well of a non-treated 6-well plate in $3 \mathrm{ml}$ pre-warmed AM culture medium (see Recipes).

Note: Typically, $3 \times 10^{5}-4 \times 10^{5}$ cells are plated in 1 well of a 6 -well plate. If BAL cells of several mice are pooled, 1.1-1.2 million cells can be plated in a non-treated $94 \mathrm{~mm}$ Petri dish in $10 \mathrm{ml}$ pre-warmed AM culture medium.

3. Add gentamicin to the AM culture $(1: 1,000)$.

Note: Gentamicin is omitted after the first medium change.

4. Incubate at $37^{\circ} \mathrm{C}, 5 \% \mathrm{CO}_{2}$.

5. Replace culture supernatant after 6-18 $\mathrm{h}$ with fresh AM culture medium and discard the supernatant.

Note: Cells will adhere fully within a few hours after the first plating and we do not keep cells in suspension at the first medium exchange. However, for subsequent medium exchanges, the cells in the supernatant are collected as well since a typical AM culture consists of both adherent and suspended cells (see also Notes section).

6. Change medium every 2 days until the cell culture reaches confluency.

7. To change medium, transfer the medium and suspension cells into a $15 \mathrm{ml}$-tube. Add $2 \mathrm{ml}$ warm AM culture medium to the well with adherent cells to prevent drying-out. Collect the suspension 
cells using centrifugation at $300 \times g 5$ min. Resuspend the pelleted cells in $1 \mathrm{ml}$ warm AM culture medium and combine with adherent cells.

Note: Freshly harvested primary AM will double every 7-10 days (Soucie et al., 2016). If the majority of AM appear stretched (spindle-like) and activated, increasing the amount of conditioned medium or adding recombinant GM-CSF might help; however, proliferative capacity will be limited and it might advisable to start a new culture (see Figure 3 for exemplary images of early AM culture).

A

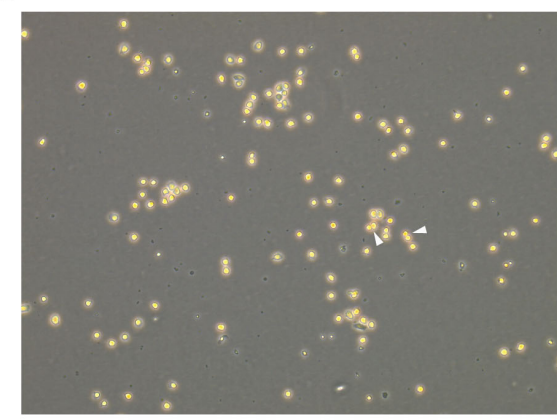

C

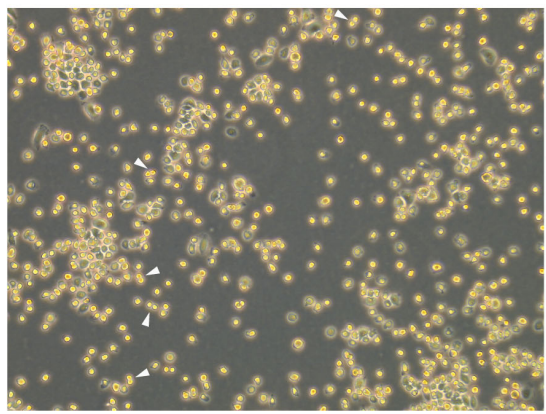

B

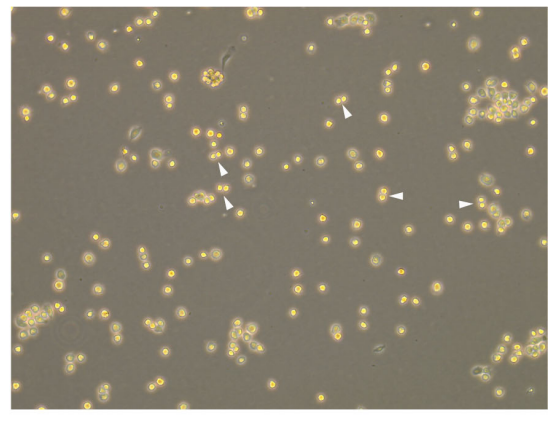

D

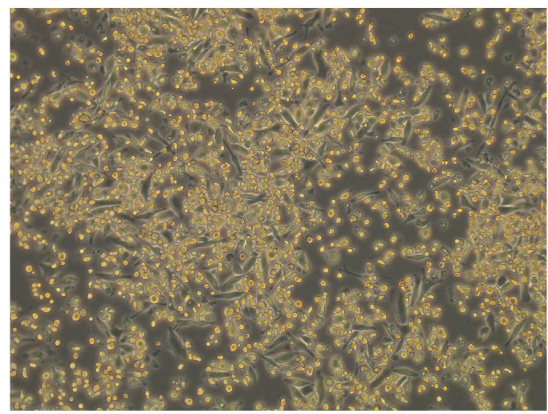

Figure 3. Representative images of AM culture within the first days after plating the cells.

A. AM culture with predominantly round-shaped cells that are partly floating and partly adherent on Day 1 after plating. B. Same culture as (A) on Day 2. C. Same culture as (A) on Day 4. D. Example for an AM culture with a large fraction of elongated, dark cells on Day 4 after plating. Arrowheads indicate dividing cells, $100 \times$ magnification.

8. To detach cells from a confluent well, collect suspension cells into a 15-ml tube.

9. Add $750 \mu \mathrm{l}$ detachment medium (see Recipes) to 1 well of a 6 -well plate (or $3 \mathrm{ml}$ to a $94 \mathrm{~mm}$ Petri dish) and incubate for $10-30 \mathrm{~min}$ at $37^{\circ} \mathrm{C}$.

Note: $A M$ are very adherent and prone to rupture when using too harsh detachment procedures. Thus, the use of non-treated plastic ware and proper detachment medium is important (see Recipes). Ruptured cells in the culture medium might affect both activation status and proliferative capacity of $A M$.

10. Detachment of cells can be supported by pipetting on the plastic bottom gently to avoid cellular damage (see Notes).

11. Pool detached cells with cells in suspension and centrifuge cells at $300 \times g$ for 5 min. 
12. Resuspend cell pellet in $1 \mathrm{ml}$ warm AM cultured medium and take a sample for counting using a hemocytometer chamber after staining with Trypan Blue to exclude dead cells. Count only live (Trypan-Blue negative) cells.

13. If the cell number has doubled, add $5 \mathrm{ml}$ warm AM culture medium and split into 2 wells of a 6well plate (or correspondingly to $2 \times 94 \mathrm{~mm}$ Petri dishes). In general, the cell number plated is maintained around the values indicated above in the note to Step C2.

Note: Earlier, we could show that AM culture remains proliferative for at least 10 passages (Soucie et al., 2016). Since then, we have experience with AM cultures that remain proliferative even beyond 20 passages with no indication of a decline in proliferative capacity.

\section{Data analysis}

Harvested cells were counted manually using a hemocytometer and considering only Trypan-Bluenegative cells. Stained cells were recorded on a BD LSRFortessa with 5 lasers using BD FACSDiva software and analyzed using FlowJo v10. Microscope images were acquired on an inverse microscope (Leica DMi1) equipped with a digital camera (MC120). Gating was performed as indicated in Figure 2A. To test for statistically significant differences between the means of three groups (Figure 1), one-way ANOVA with Tukey's multiple comparisons test was performed using GraphPad Prism 7. No data points were excluded.

\section{Notes}

1. Proliferative AM are round-shaped and semi-adherent. Re-plating of suspension AM will result in part of the cells attaching to the new well, while the other part remains in suspension. Take care to not lose the suspended cells when changing medium as this will reduce the number of proliferative cells and slow the expansion of the culture.

2. When detaching cells, do not pipet the cell suspension up and down extensively, this might affect the viability of the culture; if cells do not detach readily, collect detachment medium containing already detached cells and perform another round of incubation with fresh detachment medium and/or increase the incubation time. Late-passage cells require shorter incubation times ( $5 \mathrm{~min}$ ) than early-passage cultures (up to $30 \mathrm{~min}$ ).

3. The percentage of conditioned medium should be titrated after preparation of each batch by testing the growth of AM in the presence of various amounts of conditioned medium (e.g., 1, 2, $5,10 \%$ in complete medium). In our batches, we use typically $1 \%-3 \%$ conditioned medium diluted into complete medium (e.g., $100 \mu \mathrm{l}$ in $10 \mathrm{ml}$ ), which corresponds roughly to $2-5 \mathrm{ng} / \mathrm{ml}$ purified recombinant mouse GM-CSF.

4. We successfully replaced conditioned medium with $20 \mathrm{ng} / \mathrm{ml}$ recombinant GM-CSF (Peprotech) for long-term culture. Lower GM-CSF concentrations might be sufficient but have not been tested. 


\section{Recipes}

1. BAL buffer

PBS

2 mM EDTA (dilute 1:250 from 0.5 M EDTA stock solution)

$0.5 \%$ Fetal bovine serum (FBS)

Sterile-filter using vacuum filtration and keep at $4{ }^{\circ} \mathrm{C}$ until use

2. Complete medium

RPMI 1640

1x GlutaMAX

1x Pyruvate

1x Penicillin/Streptomycin

$10 \%$ FBS

Sterile-filter using vacuum filtration and keep at $4{ }^{\circ} \mathrm{C}$ until use

3. AM culture medium

Supplement complete medium with $1-5 \%$ conditioned medium containing mouse GM-CSF (needs to be titrated)

Pre-warm an aliquot in a water bath to $37^{\circ} \mathrm{C}$ before use

4. Detachment medium

ESGRO Complete Accutase

1 mM EGTA (dilute 1:500 from 0.5 M EGTA stock solution)

Aliquot and freeze at $-20^{\circ} \mathrm{C}$. Pre-warm an aliquot in the water bath to $37^{\circ} \mathrm{C}$ before use

\section{Acknowledgments}

We thank Stephanie Vargas Aguilar and Sethuraman Subramanian for technical discussions and helpful comments on the manuscript, Philippe Pierre for J558L cells, and the flow cytometry and animal caretaking facilities of the Max-Delbrück-Centrum for assistance. This study was supported by institutional grants from Institut National de la Santé et de la Recherche Médicale, Centre National de la Recherche Scientifique, and Aix-Marseille University to the CIML and grants to M.H. Sieweke from the Agence Nationale de la Recherche (ANR-11-BSV3-0026 and ANR-17-CE150007-01), the Institut National du Cancer (InCA13-10/405/AB-LC-HS), Fondation pour la Recherche Médicale (DEQ. 20110421320), and the European Research Council (ERC) under the European Union's Horizon 2020 research and innovation program (grant agreement number 695093 MacAge). K. Molawi was supported by a Human Frontier Science Program long-term fellowship and Stiftung Charité, L. Geiersdottir by the Fondation ARC pour la Recherche sur le Cancer. M.H. Sieweke is a Berlin Institute of Health-Einstein visiting fellow at MDC and an Alexander von Humboldt Professor at TU Dresden. 


\section{Competing interests}

The authors declare no competing financial interests.

\section{Ethics}

Animal husbandry and mouse work were conducted in accordance with the German Animal Welfare legislation, after the approval by the Landesamt für Gesundheit und Soziales (for work in Berlin, following the guidelines of the Institutional Animal Care and Use Committee of the Max Delbrück Centrum für Molekulare Medizin) and after the approval by the Landesdirektion Sachsen (for work in Dresden).

\section{References}

1. Aziz, A., Soucie, E., Sarrazin, S. and Sieweke, M. H. (2009). MafB/c-Maf deficiency enables self-renewal of differentiated functional macrophages. Science 326(5954): 867-871.

2. Baumbach, W. R., Keath, E. J. and Cole, M. D. (1986). A mouse c-myc retrovirus transforms established fibroblast lines in vitro and induces monocyte-macrophage tumors in vivo. $J$ Virol 59(2): 276-283.

3. Baumbach, W. R., Stanley, E. R. and Cole, M. D. (1987). Induction of clonal monocytemacrophage tumors in vivo by a mouse c-myc retrovirus: rearrangement of the CSF-1 gene as a secondary transforming event. Mol Cell Biol 7(2): 664-671.

4. Dong, Y., Poon, G. F. T., Arif, A. A., Lee-Sayer, S. S. M., Dosanjh, M. and Johnson, P. (2018). The survival of fetal and bone marrow monocyte-derived alveolar macrophages is promoted by CD44 and its interaction with hyaluronan. Mucosal Immunol 11(3): 601-614.

5. Fejer, G., Wegner, M. D., Gyory, I., Cohen, I., Engelhard, P., Voronov, E., Manke, T., Ruzsics, Z., Dolken, L., Prazeres da Costa, O., Branzk, N., Huber, M., Prasse, A., Schneider, R., Apte, R. N., Galanos, C. and Freudenberg, M. A. (2013). Nontransformed, GM-CSF-dependent macrophage lines are a unique model to study tissue macrophage functions. Proc Natl Acad Sci U S A 110(24): E2191-2198.

6. Guilliams, M., De Kleer, I., Henri, S., Post, S., Vanhoutte, L., De Prijck, S., Deswarte, K., Malissen, B., Hammad, H. and Lambrecht, B. N. (2013). Alveolar macrophages develop from fetal monocytes that differentiate into long-lived cells in the first week of life via GM-CSF. J Exp Med 210(10): 1977-1992.

7. Han, H. and Ziegler, S. F. (2013). Bronchoalveolar lavage and lung tissue digestion. Bio-protocol 3(16): e859.

8. Happle, C., Lachmann, N., Skuljec, J., Wetzke, M., Ackermann, M., Brennig, S., Mucci, A., Jirmo, A. C., Groos, S., Mirenska, A., Hennig, C., Rodt, T., Bankstahl, J. P., Schwerk, N., Moritz, T. and Hansen, G. (2014). Pulmonary transplantation of macrophage progenitors as effective and 
long-lasting therapy for hereditary pulmonary alveolar proteinosis. Sci Trans/ Med 6(250): 250ra113.

9. Hashimoto, D., Chow, A., Noizat, C., Teo, P., Beasley, M. B., Leboeuf, M., Becker, C. D., See, P., Price, J., Lucas, D., Greter, M., Mortha, A., Boyer, S. W., Forsberg, E. C., Tanaka, M., van Rooijen, N., Garcia-Sastre, A., Stanley, E. R., Ginhoux, F., Frenette, P. S. and Merad, M. (2013). Tissue-resident macrophages self-maintain locally throughout adult life with minimal contribution from circulating monocytes. Immunity 38(4): 792-804.

10. Hodge, S., Hodge, G., Ahern, J., Jersmann, H., Holmes, M. and Reynolds, P. N. (2007). Smoking alters alveolar macrophage recognition and phagocytic ability: implications in chronic obstructive pulmonary disease. Am J Respir Cell Mol Biol 37(6): 748-755.

11. Imperatore, F., Maurizio, J., Vargas Aguilar, S., Busch, C. J., Favret, J., Kowenz-Leutz, E., Cathou, W., Gentek, R., Perrin, P., Leutz, A., Berruyer, C. and Sieweke, M. H. (2017). SIRT1 regulates macrophage self-renewal. EMBO J 36(16): 2353-2372.

12. Jhingran, A., Kasahara, S. and Hohl, T. M. (2016). Flow cytometry of lung and bronchoalveolar lavage fluid cells from mice challenged with fluorescent Aspergillus reporter (FLARE) conidia. Bio-protocol 6(18): e1927.

13. Kopf, M., Schneider, C. and Nobs, S. P. (2015). The development and function of lung-resident macrophages and dendritic cells. Nat Immunol 16(1): 36-44.

14. Machiels, B., Dourcy, M., Xiao, X., Javaux, J., Mesnil, C., Sabatel, C., Desmecht, D., Lallemand, F., Martinive, P., Hammad, H., Guilliams, M., Dewals, B., Vanderplasschen, A., Lambrecht, B. N., Bureau, F. and Gillet, L. (2017). A gammaherpesvirus provides protection against allergic asthma by inducing the replacement of resident alveolar macrophages with regulatory monocytes. Nat Immunol 18(12): 1310-1320.

15. Mbawuike, I. N. and Herscowitz, H. B. (1989). MH-S, a murine alveolar macrophage cell line: morphological, cytochemical, and functional characteristics. J Leukoc Biol 46(2): 119-127.

16. Qian, G., Jiang, W., Zou, B., Feng, J., Cheng, X., Gu, J., Chu, T., Niu, C., He, R., Chu, Y. and Lu, M. (2018). LPS inactivation by a host lipase allows lung epithelial cell sensitization for allergic asthma. J Exp Med 215(9): 2397-2412.

17. Ralph, P. and Nakoinz, I. (1975). Phagocytosis and cytolysis by a macrophage tumour and its cloned cell line. Nature 257(5525): 393-394.

18. Raschke, W. C., Baird, S., Ralph, P. and Nakoinz, I. (1978). Functional macrophage cell lines transformed by Abelson leukemia virus. Cell 15(1): 261-267.

19. Rayasam, A. (2015). Isolating and culturing dendritic cells (Dendritic Cell J558 Protocol). Protoc Exch 22-24.

20. Schneider, C., Nobs, S. P., Heer, A. K., Kurrer, M., Klinke, G., van Rooijen, N., Vogel, J. and Kopf, M. (2014a). Alveolar macrophages are essential for protection from respiratory failure and associated morbidity following influenza virus infection. PLoS Pathog 10(4): e1004053.

21. Schneider, C., Nobs, S. P., Kurrer, M., Rehrauer, H., Thiele, C. and Kopf, M. (2014b). Induction of the nuclear receptor PPAR-y by the cytokine GM-CSF is critical for the differentiation of fetal 
monocytes into alveolar macrophages. Nat Immunol 15(11): 1026-1037.

22. Soucie, E. L., Weng, Z., Geirsdottir, L., Molawi, K., Maurizio, J., Fenouil, R., Mossadegh-Keller, N., Gimenez, G., VanHille, L., Beniazza, M., Favret, J., Berruyer, C., Perrin, P., Hacohen, N., Andrau, J. C., Ferrier, P., Dubreuil, P., Sidow, A. and Sieweke, M. H. (2016). Lineage-specific enhancers activate self-renewal genes in macrophages and embryonic stem cells. Science 351(6274): aad5510.

23. Steele, C., Marrero, L., Swain, S., Harmsen, A. G., Zheng, M., Brown, G. D., Gordon, S., Shellito, J. E. and Kolls, J. K. (2003). Alveolar macrophage-mediated killing of Pneumocystis carinii f. sp. muris involves molecular recognition by the Dectin-1 ß-glucan receptor. J Exp Med 198(11): 1677-1688.

24. Stockinger, B., Zal, T., Zal, A. and Gray, D. (1996). B cells solicit their own help from T cells. $J$ Exp Med 183: 891-899.

25. Sun, F., Xiao, G. and Qu, Z. (2017). Murine bronchoalveolar lavage. Bio-protocol 7(10): e2287.

26. Sun, K. and Metzger, D. W. (2008). Inhibition of pulmonary antibacterial defense by interferony during recovery from influenza infection. Nat Med 14(5): 558-564.

27. Suzuki, T., Arumugam, P., Sakagami, T., Lachmann, N., Chalk, C., Sallese, A., Abe, S., Trapnell, C., Carey, B., Moritz, T., Malik, P., Lutzko, C., Wood, R. E. and Trapnell, B. C. (2014). Pulmonary macrophage transplantation therapy. Nature 514(7523): 450-454.

28. Tibbitt, C. and Coquet, J. M. (2016). House dust mite extract and cytokine instillation of mouse airways and subsequent cellular analysis. Bio-protocol 6(14): e1875.

29. van de Laar, L., Saelens, W., De Prijck, S., Martens, L., Scott, C. L., Van Isterdael, G., Hoffmann, E., Beyaert, R., Saeys, Y., Lambrecht, B. N. and Guilliams, M. (2016). Yolk sac macrophages, fetal liver, and adult monocytes can colonize an empty niche and develop into functional tissueresident macrophages. Immunity 44(4): 755-768.

30. Walker, W. S. and Demus, A. (1975). Antibody-dependent cytolysis of chicken erythrocytes by an in vitro-established line of mouse peritoneal macrophages. J Immunol 114(2 pt 2): 765-769.

31. Yu, X. Buttgereit, A., Lelios, I., Utz, S. G., Cansever, D., Becher, B. and Greter, M. (2017). The cytokine TGF- $\beta$ promotes the development and homeostasis of alveolar macrophages. Immunity 47: 903-912.e4.

32. Yuan, X., Shan, M., You, R., Frazier, M. V., Hong, M. J., Wetsel, R. A., Drouin, S., Seryshev, A., Song, L. Z., Cornwell, L., Rossen, R. D., Corry, D. B. and Kheradmand, F. (2015). Activation of C3a receptor is required in cigarette smoke-mediated emphysema. Mucosal Immunol 8(4): 874-885.

33. Zal, T., Volkmann, A. and Stockinger, B. (1994). Mechanisms of tolerance induction in major histocompatibility complex class II-restricted T cells specific for a blood-borne self-antigen. $J$ Exp Med 180(6): 2089-2099.

34. Zhang, X., Goncalves, R. and Mosser, D. M. (2008). The isolation and characterization of murine macrophages. Curr Protoc Immunol Chapter 14: Unit 14.1. 